\title{
The Relationship Between HCV-NS5A Gene Mutations and Resistance to Combination Therapy in Patients with HCV- Genotype 1-B
}

\author{
Hamed Esmaeil Lashgarian ${ }^{1}$, Ali Valibeik ${ }^{2}$, Abdolrazagh Marzban ${ }^{3}$, \\ Maryam Karkhane ${ }^{2}$, Kiana Shahzamani*4
}

\begin{abstract}
Background: Hepatitis C virus (HCV) is one of the major causes of chronic liver disease, as it holds a significant role in developing liver cirrhosis and hepatocellular carcinoma. Combination therapy with Pegaferon and Ribavirin leads to viral clearance of only $50 \%$ of patients. During the host antiviral response, protein kinase R (PKR) interacts with eukaryotic translation initiation factor 2 alpha (eIF2 $\alpha$ ), that leads to the inhibition of viral protein synthesis. The viral NS5A protein appears to interfere with this antiviral action, evading the host immune response. However, mutations in the NS5A gene have been observed to render HCV more susceptible to treatment. The aim of this study was to determine the mutations present in the IFN Sensitivity Determining Region (ISDR) and NS5A-PKRbinding domain regions in chronic HCV infected patients before and after therapy.

Methods: Viral RNA was isolated from the plasma of 52 chronic HCV infected patients before and after treatment. RT-Nested PCR reaction was used to reverse transcription and amplification of target fragment using the specific primers.

Results: Sequence analysis revealed no relationship between NS5A mutations and response to treatment. No significant difference was found between the mutations before and 3 months after treatment among responders and non-responders.

Conclusions: This study showed that the number of mutations in NS5A did not significantly differ between the patients who responded to treatment and the patients that did not. Therefore, sequencing of these regions does not appear to be a suitable tool for predicting treatment outcomes.
\end{abstract}

Keywords: Genotype b1, Hepatitis C virus, Mutation, Non-structural protein (NS5A), Response to combination therapy.

\section{Introduction}

Hepatitis C virus (HCV) infection commonly results in the development of chronic hepatitis. With disease progression, HCV can lead to significant liver damage acting as a major factor involved in the development of liver cirrhosis and liver cancer within developed countries. According to the World
Health Organization (WHO), up to 200 million people worldwide are infected with $\mathrm{HCV}$ creating a significant global disease burden $(1,2)$. The Centers for Disease Control (CDC) indicates that there are roughly 2.4 million people living with $\mathrm{HCV}$ infection in the United States, The actual 
number may be as high as 4.7 million or as low as 2.5 million (3). As a result of this prevalence, the number of people with liver cirrhosis and liver cancer is likely to increase with time, unless significant preventive measures are taken (4). HCV is a positivesense single-stranded RNA virus belonging to the hepacivirus genus, as a member of the Flaviviridae family. The viral genome consists of an open reading frame (ORF) with 9379-9379 nucleotides. At the two ends of the genome, it contains untranslated regions (UTRs) which surround an ORF encoding for a polyprotein 3000 amino acids in length (5). Similar to other RNA viruses, HCV is error prone as it does not have the ability to correct replication errors contributing to its high mutation rate. Due to this nature, proliferation of the virus in persistent infections can lead to the emergence of a genetically diverse population of viral particles, known as a Quasispecies. This vast genetic diversity creates significant challenges in the treatment of $\mathrm{HCV}$ infection, and is thus a major area of focus of research. Nucleotide studies have shown that the recovery from acute $\mathrm{HCV}$ infection is accompanied by an overall decrease in viral quasispecies, whereas the progression of the disease to chronic infection and resistance to interferon (IFN) therapy is accompanied by an increase in the quasispecies population. This suggests that in the case of chronic infection and therapeutic resistance, the selection pressures have led to the viral variants evolving to escape the host's immune system and develop a resistance to IFN therapy (6). The nonstructural gene 5A (NS5A) is one of the genomic regions of the virus that is mutated in response to IFN therapy. NS5A encodes for a protein, from amino acid 1973-2419 on HCV. NS5A has three functional domains:1- regulation of viral genome replication, 2- IFN resistance, 3Apoptosis (7). Within the cytoplasm of HCV infected cells, NS5A exists in two different states, hypo phosphorylation (p56) and hyper phosphorylation (p58) (8).

The region of nucleotides between 2209 and 2248 is well known as the IFN Sensitivity
Determining Region (ISDR) within the protein kinase $\mathrm{R}$ binding domain (PKRBD) of HCV-1b. Previous research has highlighted that the genetic heterogeneity of NS5A is correlated with the therapeutic outcomes of both IFN and non-IFN treatments $(9,10)$. Amino acid 66 at the carboxyl end of the NS5A gene is called PKRBD, which binds to protein kinase $R$ (PKR). PKR is one of the host's innate immune defenses against viral infections (11).

The binding of IFNs to their receptors leads to the induction of IFN-stimulated genes (ISGs). One such ISG in the PKR gene, which has an affinity for the viral PKRBD located in the NS5A protein $(12,13)$. Usually, induction of the PKR gene leads to viral protection within the host cell. PKR regulates the phosphorylation of the eukaryotic initiation factor 2 alpha (eIF2 $\alpha$ ). When phosphorylated, eIF $2 \alpha$ becomes inactivated, preventing further mRNA translation and thus, viral proteins are not synthesized. However, HCV takes advantage of this ISG by activating eIF $2 \alpha$ allowing for the production of viral proteins within the host cell. If a mutation occurs in the gene encoding for PKRBD, it will lose its ability to bind to PKR enabling the downstream antiviral action of PRK to be initiated. $(11,14)$. In addition to the presence of mutations in NS5A, the number of mutations within the PKRBD or ISDR gene also appear to be critical in determining the extend of viral clearance. Research by Enomoto et al (1995) observed that in Japanese patients infected with $\mathrm{HCV}-1 \mathrm{~b}$, those that had 4 or more mutations within the ISDR gene of NS5A experienced a successful therapeutic outcome, while those with fewer mutations were non-responders to IFN monotherapy. The predictive value of ISDR $\geq$ 4 was replaced by ISDR $\geq 2$ in sustained virologic response (SVR) cases. Therefore, ISDR $\geq 2$ were assumed to be sensitive variants and patients with $\mathrm{ISDR} \leq 1$ were considered to have resistant variants for pegIFN therapy (15).

Determining the mutations present in the NS5A gene in patients with HCV who are 
receiving combination therapy of IFN with ribavirin is of particular importance. The presence of mutations found in this gene have been shown to be highly effective in predicting susceptibility to treatment in $\mathrm{HCV}$ infected patients. As a result, there is the potential to decrease the progression from $\mathrm{HCV}$ infection to chronic liver disease and liver cancers such as hepatocellular carcinoma. Therefore, examining the mutations within the NS5A gene before and throughout the course of treatment may help predict treatment response and monitor the effectiveness of antiviral drug therapy (16). Therefore, the aim of this study was to investigate the pattern of mutations in the PKRBD and ISDR region of the NS5A gene in $\mathrm{HCV}$ infected patients throughout their course of combined IFN and Ribavirin treatment to explore the relationship between these mutations and resistance to therapy in Iranian patients with $\mathrm{HCV}-1$ genotype. If mutations occur in NS5A, the virus gene has an IFN resistance pattern. This would prevent the unnecessary use of high-dose drugs and reduce the extent of their side effects $(17,18)$.

\section{Materials and Methods Study population}

Patients with chronic HCV infection who were referred to Tehran University of Medical Sciences were included in the study population. The patients were evaluated before and after treatment with Peginterferon (peg-IFN) and Ribavirin antiviral therapy. A total of 52 patients were included in this study. All patients were examined by a gastroenterologist who assessed the clinical symptoms and laboratory findings and confirmed the presence of chronic HCV. Following this, the patients' personal information was recorded in a questionnaire which was kept confidential. Finally, blood samples were collected from each patient, once before treatment and once three months after treatment. Prior to sampling, informed consent was obtained from each patient using a consent letter outlining the overall goals and procedures involved in the study. (FWA00001331, DHHSIRB00001641). For 25 patients, the treatment was so effective so that viral load within the blood could not be detected by sensitive methods rendering these samples unusable for the purposes of this study. One patient was excluded from the study because of pregnancy, 2 patients couldn't tolerate side effects and dismissed the therapy. In 24 patients, HCV RNA were detected 48 weeks after treatment and didn't achieve SVR.

\section{Sample preparation}

Blood samples were drawn into sterile tubes containing EDTA anticoagulant. The tubes were centrifuged at $3000 \mathrm{rpm}$ for plasma separation. The isolated plasma samples were then stored at $-70{ }^{\circ} \mathrm{C}$ until further analysis.

\section{Hepatitis C virus RNA isolation}

Viral RNA extraction was performed with the guanidium-isothiocyanate method. In this study, the HCV- RNA isolation was achieved using the QIAamp Viral RNA mini kit (Qiagen, Germany) according to the manufacturer's instructions. The extracted RNA was stored at $-70{ }^{\circ} \mathrm{C}$ until cDNA synthesis.

\section{cDNA synthesis}

The extracted RNA was immediately used for reverse transcription and cDNA synthesis using the cDNA synthesis kit (Roche, Germany). It should be noted that random hexamers were used as the primer for cDNA synthesis. The final reaction mixture consisted of $4 \mu \mathrm{L}$ of $5 \mathrm{x}$ RT buffer, $2 \mu \mathrm{L}$ DTT (Dithiothreitol), $2 \mu \mathrm{L}$ of $10 \quad \mathrm{mM}$ deoxyribonucleotide (dNTP), $1 \mu \mathrm{L}$ of Random hexamer, $0.5 \mu \mathrm{L}$ of RNasin at a concentration of $40 \mathrm{U} / \mu \mathrm{L}, 1 \mu \mathrm{L}$ of $\mathrm{RT}$ enzyme at a concentration of $200 \mathrm{U} / \mu \mathrm{L}$, and $9.5 \mu \mathrm{L}$ of extracted RNA at a concentration of $10 \mathrm{pg} / \mu \mathrm{L}$. All the mentioned materials, except the RT enzyme, were immersed in a $0.2 \mathrm{ml}$ microtube for $5 \mathrm{~min}$ at $95{ }^{\circ} \mathrm{C}$ in a thermocycler. Next, the RT enzyme was added and the microtubes were incubated at $42{ }^{\circ} \mathrm{C}$ for one hour. The test was finished at $10{ }^{\circ} \mathrm{C}$ for $10 \mathrm{~min}$. Finally, synthesized cDNA was stored at $-70^{\circ} \mathrm{C}$. 
Design of specific primers for nested PCRFirst, HCV sequences were collected from the NCBI and Los alamos gene databases. All sequences were collected using the Mega3.1 software then sequenced (Align) to find conserved areas within the NS5A region.
These conserved areas were used for primer designing. Gene Runner, Oligo 6, and Oligo online software were used to design the primers. Primer designing was performed using the NCBI Primer-BLAST online databases (Table 1).

Table 1. The sequence of primers used for HCV-b1 genome amplification by Nested PCR.

\begin{tabular}{lllll}
\hline Nested PCR & Primer & Sequence & Nucleotide & Length \\
\hline $\begin{array}{l}\text { First Round } \\
\text { (External primers) }\end{array}$ & Forward H1 & 5'-AGGCGGCTGGGAGAAGGTTGG -3' & $6632-7690$ & 1058 bp \\
\hline Reverse H2 & 5-CTCTACCAGCGGGGGGTTGTAGTCC -3' & & \\
\hline $\begin{array}{l}\text { Second Round } \\
\text { (Internal primers) }\end{array}$ & Forward H3 & 5'-CTGATCCCTCCCATATAACAGC -3' & $6889-7633$ & 744 bp \\
\hline
\end{tabular}

\section{RT-Nested PCR reaction}

\section{A) First Round PCR Reaction}

External primers were used at this stage. The primary master-mix included $2.5 \mu \mathrm{l}$ of $10 \mathrm{x}$ PCR Buffer, $1 \mu \mathrm{l}$ of $10 \mathrm{mM}$ dNTP, $0.7 \mu \mathrm{L}$ $\mathrm{MgCl} 2$ at a concentration of $50 \mathrm{mM}, 0.5 \mu \mathrm{L}$ of each of the external primers at a concentration of $20 \mathrm{pmol} / \mu \mathrm{L}, 0.2 \mu \mathrm{L}$ of Taq polymerase at a concentration of 5 units $/ \mu 1$, and $5 \mu \mathrm{l}$ of cDNA at a concentration of $25 \mathrm{ng} / \mu \mathrm{L}$. The final volume of the mixture was increased to $25 \mu \mathrm{L}$ with double distilled water (ddH2O). The timing for the first round is as follows: initial denaturation at $95{ }^{\circ} \mathrm{C}$ for 30 seconds, 35 cycles of 45 seconds at $94{ }^{\circ} \mathrm{C}, 45$ seconds at $54{ }^{\circ} \mathrm{C}$ and 45 seconds at $72{ }^{\circ} \mathrm{C}$, and finally a final elongation phase of 5 minutes at $72^{\circ} \mathrm{C}$.

B) The second round of PCR Reaction

Internal primers were used at this stage. The primary master-mix included $2.5 \mu 110 \mathrm{x}$ PCR Buffer 10x, $1 \mu 110 \mathrm{mM}$ deoxyribonucleotide, $0.75 \mu \mathrm{L} \mathrm{MgCl} 2$ at a $50 \mathrm{mM}$ concentration, 0.5 $\mu \mathrm{L}$ of each of the external primers at a concentration of 20 picomol $/ \mu 1,0.3 \mu 1$ of Taq DNA polymerase enzyme at a concentration of 5 units $/ \mu 1$, and $3 \mu 1 \mathrm{cDNA}$ at a concentration of $25 \mathrm{ng} / \mu \mathrm{l}$. The final volume of the mixture was increased to $25 \mu \mathrm{l}$ with ddH2O. The timing of the thermocycler device for the second round is as follows: initial denaturation at $95{ }^{\circ} \mathrm{C}$ for
30 seconds, 35 cycles of 45 seconds at $94{ }^{\circ} \mathrm{C}$, 45 seconds at $54{ }^{\circ} \mathrm{C}$, and 45 seconds at $72{ }^{\circ} \mathrm{C}$. There was one final elongation step for 5 minutes at $72{ }^{\circ} \mathrm{C}$. It is worth noting that the amounts used in the final mixture and the appropriate time schedule for this reaction were determined after in depth investigation and optimization of the method. It should be noted that in each experiment, a negative control (normal serum), a non-template control (NTC), and a positive control for the Nested PCR stage were tested along with patient samples during the different stages of the molecular experiments.

\section{Electrophoresis on agarose gel}

To investigate the results, $10 \mu \mathrm{L}$ of the second round PCR product was transferred onto $1.5 \%$ agarose electrophoresis gel. The samples were run through the gel at $80 \mathrm{~V}$. The gel was then examined under UV light using a gel documentation system.

\section{Sequencing of HCV-genome}

After viewing the specific band, all the PCR product obtained from the second round of nested-PCR were transferred to SEQLAB Germany Company with Armin Shegerf's representative. 


\section{Results}

\section{RT-Nested PCR of patient samples}

After performing optimization tests and determining the optimal test conditions, RT
Nested PCR was performed on patient samples. The presence of the $744 \mathrm{bp}$ band confirms the accuracy of the Nested-PCR Reaction (Fig. 1).

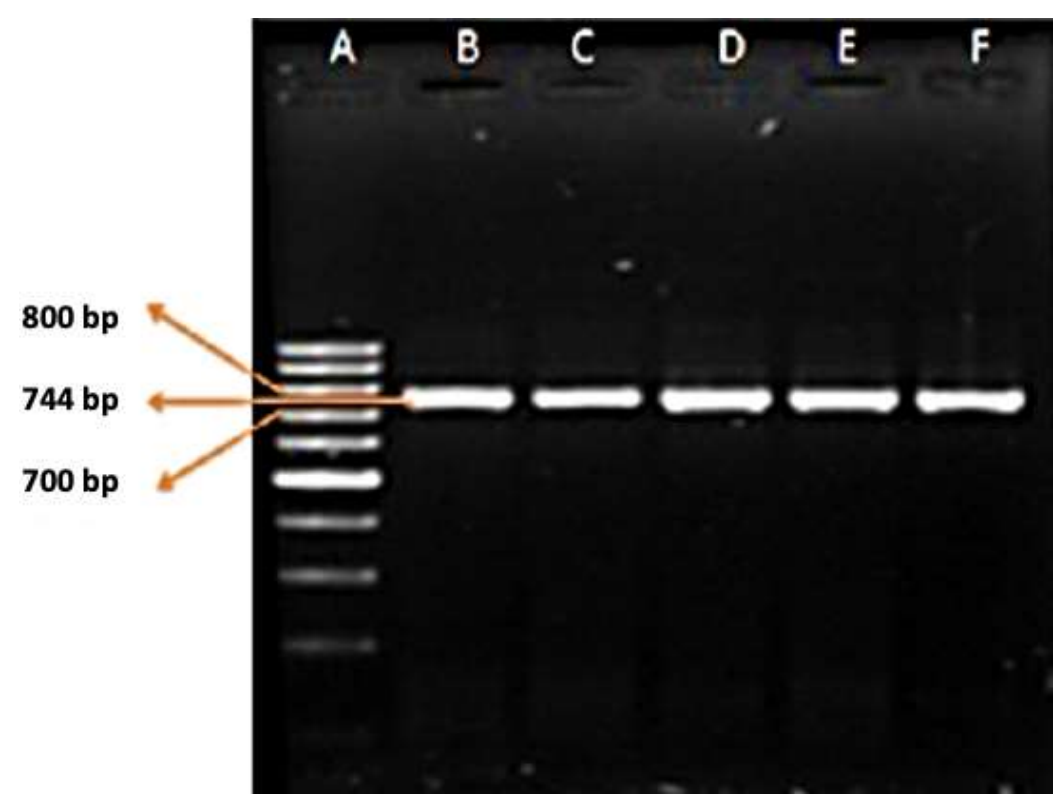

Fig. 1. Results of NS5A gene amplification by RT-Nested PCR of the HCV-b1 genotype. A) 100bp DNA marker B to F) patient samples with 744 bp length.

\section{Data analysis}

In this study, data was analyzed after the amplification of codons 2209 to 2274 of the PKRBD region extracted from the plasma of 24 $\mathrm{HCV}$ patients. All patients had the HCV genotype $1 \mathrm{~b}$ confirmed on behalf of the Keivani Lab using the PCR-RFLP method. Sequences obtained by Clustal X software were also sequenced (19). Sequences of genes were compared with genotype reference $1 \mathrm{~b}$ with identification number AF009606 and a fixed sequence obtained from sequencing each patient (20). According to studies, the area is divided into two parts (13):

1- ISDR or the IFN Sensitivity Determining Region 2- 26 downstream ISDR amino acids were comprising codons 2246 to 2274 .

After examining the number of amino acids transposed in ISDR among responders and resistant individuals, it was found that only $3 \%$ of the ISDR sequences resembled the wild-type or primary type of the virus, indicating substitutions in this area. In most patients The Number of transitions in amino acids was over 2. However, this appeared to be unrelated to treatment response. According to Enomoto et al., ISDR sequences of patients are divided into 3 categories following the course of treatment:

1. Wild type: After combined treatment, no shift in amino acid sequence occurred.

2. Intermediate Type: The number of transitions in this sequence is 1 to 3 amino acids.

3. Mutant Type: The number of transitions in this sequence is 4 to 6 amino acids.

In this study, the percentage of patients in the first, second and third groups were 30\%, 60\% and $10 \%$, respectively. However, no association was observed between the treatment responders and non-responders (Table 2). The same situation was observed in the 26 amino acids downstream of the ISDR (Table 3).

Overall, our findings from sequencing patients treated with combination therapy showed that there was no relationship between mutations in the PKR region and treatment 
response. The same results were observed for

the ISDR sequence.

Table 2. Amino acid transition in NS5A-ISDR and response to combination therapy.

\begin{tabular}{lcc}
\hline Type (number of transition) & Non-responder & Responder \\
\hline Wild (0) & 5 & 4 \\
Intermediate (1-3) & 14 & 4 \\
Mutant (4-6) & 2 & 1 \\
\hline
\end{tabular}

Table 3. Amino acid transition at 26 downstream NS5A-ISDR amino acids and response to combination therapy.

\begin{tabular}{|c|c|c|}
\hline Type & Non-responder & Responder \\
\hline Wild & 1 & 0 \\
\hline Intermediate & 9 & 4 \\
\hline Mutant & 4 & 1 \\
\hline
\end{tabular}

\section{Discussion}

Infection with HCV remains a major disease burden worldwide contributing to significant morbidity and mortality associated with liver disease, including liver cirrhosis and hepatocellular carcinoma. Most new cases of infection are currently within developing countries; however, the high incidence of migration contributes to its spread worldwide. In developed countries, HCV infection accounts for 50 to $75 \%$ of liver cancer cases and twothirds of liver transplants. The standard treatment of $\mathrm{HCV}$ positive patients involves the concomitant use of pegylated-IFN and ribavirin. The use of combination therapy results in an increase in the response to treatment compared to monotherapy of either IFN or ribavirin alone (21). Many factors such as patient age, sex, weight, viral load prior to treatment, and viral genotype contribute to how an individual responds to treatment (22). In 1996, Matsumoto and colleagues proposed that certain viral host factors (such as HLA-G, MXA and CTLA-4 haplotypes) are more likely to result in resistance to therapy (23-25). Hutchison and colleagues also noted that patients were more resistant to IFN treatment with the viral subtype 1bcompared to the subtype1 a (26). It was later shown that HCV encodes for proteins capable of inhibiting the IFN-induced PKR antiviral protein, therefore reducing the antiviral effects of IFN. PKR is one of the intracellular kinases that is produced after IFN binds to its receptor in the cell. Activation of the kinase induces the phosphorylation of the translation initiation factor, eIF $2 \alpha$, which inhibits protein synthesis and subsequently halts viral replication within infected cells preventing viral replication (27). In fact, induction of PKR is one of the most critical ways in which IFN protects cells against RNA viral infection. If this pathway is blocked by viral proteins, the antiviral functions of IFN are significantly impaired. Both NS5A and E2 proteins have regions that inhibit PKR phosphorylation of eIF2 $\alpha$. The NS5A protein contains PKR-BD, which is capable of binding to PKR, thereby inhibiting its activity. In fact, the interaction of viral proteins with PKR is one of the viral evasion strategies used to escape this antiviral system of IFN and PKR (28). As these areas of the virus change due to mutation, the virus's ability to evade the effects of IFN decreases, which provides the opportunity for IFN treatment to function effectively. If mutations occurring in these regions result in an altered amino acid sequence, the interaction of viral proteins and PKR is disrupted. Under these conditions, PKR targets its own phosphorylation activity and eIF2 $\alpha$, which leads to viral protein blockade. Therefore, unchanged ISDR and PKR-BD sequences in the NS5A 
protein are effective in establishing treatment resistance. Increasing the number of mutations in these areas results in the virus being more susceptible to treatment. For this reason, many studies have been performed to understand the genetic variation of different regions of the HCV genome, especially NS5A (29). This study was designed to evaluate the potential of these sequences as indicators of treatment response (29). However, this association has been more frequently investigated in $\mathrm{HCV}$ genotype 1 variants as this region is more homologous with PKR and eIF2 $\alpha$ (30). In this study, ISDR was evaluated in the patients treated with Pegaferon land ribavirin, 24 of which did not respond to treatment. Examining the amino acid sequences of patients before treatment indicated that there were no significant differences between the patients who did respond to treatment versus those who did not. Comparison of the amino acid sequence of this region did not show any changes before or 3 months after treatment between treatment responders and non-responders. Our findings indicating a lack of genetic mutations within this region corroborates the observations from previous studies. Genetic stability of this region and a lack of correlation with treatment response indicates that sequencing of this region before treatment is not a useful indicator for clinical decision making or the evaluation of therapeutic outcomes.

Since other factors have the potential to affect response to antiviral therapy, they were also considered in the study. These included, age, sex, viral load, and the number of mutations. Of the 24 patients, only 2 were female, both of which responded for combination therapy. Therefore, sex do not have an influence on the occurrence of infection and resistance to therapy. The mean age of the patients that responded to treatment was less than 40 years, while the mean age of the nonresponder group was over 40 years. A total of 9 patients had no mutations in the PKRBD region, 8 of which were over 40 years old. Our findings indicate this relationship to be statistically significant, therefore age appears to be an important factor in determining treatment response. According to the index described by Enomoto et al., most of the patients in this study had intermediate ISDR and only $10 \%$ of the patients had mutations. Significant research efforts have been dedicated to understanding the ISDR mutations and their relationship to treatment. However, the results have been inconsistent. Japanese studies have shown a correlation between the number of ISDR mutations and response to IFN treatment in patients infected with the $\mathrm{HCV}$ genotype 1 variant (23). These findings have not been confirmed by most studies in Western, American, and Turkish countries (31, 32). Research by Murayama et al. found a clear link between the number of ISDR mutations in Japan type (J-type) and response to IFN therapy (32). This type of HCV strain is prevalent in Japan, however, this association has not been found in the World wide-type (W-type), which is spread more globally $(32,33)$. It appears that the importance of ISDR in predicting response to treatment depends on the geographic region (32). The HCV subtypes circulating in Iran have no resemblance to those found in neighboring countries such as Turkey and Pakistan, or those in East Asian countries such as Iraq, Saudi Arabia, Yemen and Kuwait. Rather, they are more similar to the species found in European and American countries (33). Given this similarity, it is not surprising that the results of this study are consistent with those of European and American studies. According to the literature, the relationship between response to therapy and the heterogeneity created in the NS5A sequence is related to genotypes of $\mathrm{HCV}(34,35)$. The results of the current study showed that sequencing of ISDR and PKR-BD regions in the NS5A protein alone are not predictive of treatment response. Duverlie et al. sequenced the entire NS5A region of the HCV $1 \mathrm{~b}$ virus genotype in patients who responded to treatment and those who were resistant (nonresponder) (36). Their findings showed that that the V3 region was identified as the most variable region of the NS5A gene (15). In addition, Nousbaum and colleagues found that $\mathrm{V} 3$ region amino acid translocations in $\mathrm{HCV}-1 \mathrm{a}$ 
isolates from patients responding to treatment were significantly higher than those who did not respond to treatment (16). Therefore, it is suggested that the $\mathrm{V} 3$ region be considered as the most variable region of NS5A. Our findings showed that the number of mutations in NS5A did not significantly differ between the patients who were responders or non-responders throughout their course of treatment. Therefore, amino acid sequencing of these regions does not appear to be an appropriate tool for

\section{References}

1. Thrift AP, El-Serag HB, Kanwal F. Global epidemiology and burden of $\mathrm{HCV}$ infection and HCV-related disease. Nat Rev Gastroenterol Hepatol. 2017;14(2):122-132.

2. Karkhane M, Mohebbi SR, Azimzadeh P, Niasar MS, Sarbazi MR, Sharifian A, et al. Lack of association between interleukin 28B gene polymorphisms (rs8099917G/T, rs12979860 $\mathrm{C} / \mathrm{T}$ ) and susceptibility to chronic hepatitis $\mathrm{C}$ virus infection, Tehran, Iran. Gastroenterol Hepatol Bed Bench. 2016;9(Suppl1):S29-S35.

3. Edlin BR, Eckhardt BJ, Shu MA, Holmberg SD, Swan T. Toward a more accurate estimate of the prevalence of hepatitis $C$ in the United States. Hepatology. 2015;62(5):1353-63.

4. Ip PP, Nijman HW, Wilschut J, Daemen T. Therapeutic vaccination against chronic hepatitis $C$ virus infection. Antiviral research. 2012;96(1):36-50.

5. Bartenschlager R, Lohmann V. The Hepatitis C Virus Replicon System and Its Role in Drug Development. 2019:69-96.

6. Susser S, Flinders M, Reesink HW, Zeuzem S, Lawyer G, Ghys A, et al. Evolution of hepatitis $\mathrm{C}$ virus quasispecies during repeated treatment with the NS3/4A protease inhibitor telaprevir. Antimicrob Agents Chemother. 2015;59(5):2746-55.

7. Moradpour D, Penin F, Rice C. Chapter 7Replication of Hepatitis C Virus. In: Boyer TD, Manns MP, Sanyal AJ, editors. Zakim and Boyer's Hepatology (Sixth Edition). Saint Louis: W.B. Saunders; 2012. p. 97-110.

8. Gupta SP. Chapter 3 - Inhibition of Viruses: Promising Targets and Their Importance. In: predicting treatment outcomes in patients receiving IFN and Ribavirin combination therapy.

\section{Acknowledgements}

The authors would like to thank the participants of this study for their corporation. We wish them health and well-being. This research was granted by Tehran University of Medical Sciences, Tehran, Iran.

The authors declare no conflicts of interest.

Gupta SP, editor. Studies on Hepatitis Viruses: Academic Press; 2018. p. 35-65.

9. Pawlotsky J-M, Germanidis G, Neumann AU, Pellerin M, Frainais P-O, Dhumeaux D. Interferon resistance of hepatitis $\mathrm{C}$ virus genotype 1b: relationship to nonstructural $5 \mathrm{~A}$ gene quasispecies mutations. $J$ Virol. 1998;72(4):2795-2805

10. Veillon P, Payan C, Le Guillou-Guillemette $\mathrm{H}$, Gaudy C, Lunel F. Quasispecies evolution in NS5A region of hepatitis $C$ virus genotype $1 b$ during interferon or combined interferonribavirin therapy. World J Gastroenterol. 2007;13(8):1195-1203.

11. Holysz M, Bialas K, Migdalski P, Kmieciak $\mathrm{D}$, Trzeciak W. Identification of mutations in the HVR1 and PKR-BD regions in HCV-infected patients resistant to PEG-IFN $\alpha / \mathrm{RBV}$ therapy. J Appl Genet. 2015;56(3):403-9.

12. Jarret A, McFarland AP, Horner SM, Kell A, Schwerk J, Hong M, et al. Hepatitis-C-virusinduced microRNAs dampen interferonmediated antiviral signaling. Nat Med. 2016;22(12):1475-1481.

13. Yokozaki S, Katano Y, Hayashi K, Ishigami $\mathrm{M}$, Itoh $\mathrm{A}$, Hirooka $\mathrm{Y}$, et al. Mutations in two PKR-binding domains in chronic hepatitis $\mathrm{C}$ of genotype $3 \mathrm{a}$ and correlation with viral loads and interferon responsiveness. J Med Virol. 2011;83(10):1727-32.

14. García-Sastre A. Ten strategies of interferon evasion by viruses. Cell Host Microbe. 2017;22(2):176-184.

15. de Rueda PM, Rodríguez JMF, Pérez RQ, 
Medina AG, Álvarez ABM, Ruíz JC, et al. Hepatitis C virus NS5A region mutation in chronic hepatitis $\mathrm{C}$ genotype 1 patients who are non-responders to two or more treatments and its relationship with response to a new treatment. World J Gastroenterol. 2017;23(25):4538-4547. 16. Nousbaum J-B, Polyak S, Ray S, Sullivan D, Larson A, Carithers R, et al. Prospective characterization of full-length hepatitis $C$ virus NS5A quasispecies during induction and combination antiviral therapy. J Virol. 2000;74(19):9028-38.

17. Sayan M, Yildırım FS, Akhan S, Yıldırım AA, Şirin G, Cabalak M, et al. NS5A resistance associated substitutions in chronic hepatitis $\mathrm{C}$ patients with direct acting antiviral treatment failure in Turkey. Int J Infect Dis. 2020;95:84-89.

18. Aldunate F, Echeverría N, Chiodi D, López $\mathrm{P}$, Sánchez-Cicerón A, Fajardo A, et al. Pretreatment Hepatitis C Virus NS5A/NS5B Resistance-Associated Substitutions in Genotype 1 Uruguayan Infected Patients. Dis Markers. 2018;2018:2514901.

19. Thompson JD, Gibson TJ, Plewniak F, Jeanmougin F, Higgins DG. The CLUSTAL_X windows interface: flexible strategies for multiple sequence alignment aided by quality analysis tools. Nucleic Acids Res. 1997;25(24):4876-82.

20. Choo Q, Richman K, Han J, Berger K, Lee $\mathrm{C}$, Dong $\mathrm{C}$, et al. Genetic organization and diversity of the hepatitis $\mathrm{C}$ virus. Proc Natl Acad Sci U S A. 1991;88(6):2451-2455.

21. Jabari H, Bayatian A, Sharifi AH, Zaer RH, Fakharzadeh E, Asadi R, et al. Safety and efficacy of locally manufactured pegylated interferon in hepatitis $\mathrm{C}$ patients. 2010;13(4):306-12.

22. Pascu M, Martus P, Höhne M, Wiedenmann B, Hopf U, Schreier E, et al. Sustained virological response in hepatitis $C$ virus type $1 b$ infected patients is predicted by the number of mutations within the NS5A-ISDR: a metaanalysis focused on geographical differences. Gut. 2004;53(9):1345-51.

23. Enomoto N, Sakuma I, Asahina Y, Kurosaki M, Murakami T, Yamamoto C, et al. Mutations in the nonstructural protein $5 \mathrm{~A}$ gene and response to interferon in patients with chronic hepatitis $\mathrm{C}$ virus $1 \mathrm{~b}$ infection. $\mathrm{N}$ Engl $\mathrm{J}$ Med. 1996;11;334(2):77-81.

24.Khorrami S, Mohammadpour H, Shahzamani K, Zarif MN, Sharifi AH, Merat S, et al. The relationship between HLA-G and viral loads in non-responder $\mathrm{HCV}$-infected patients after combined therapy with IFN- $\alpha 2 \alpha$ and ribavirin. Hum Immunol. 2015;76(2-3):181-6.

25. Sepahi S, Pasdar A, Gerayli S, Rostami S, Gholoobi A, Meshkat Z. CTLA-4 Gene Haplotypes and the Risk of Chronic Hepatitis C Infection; a Case Control Study. Rep Biochem Mol Biol. 2017;6(1):51-58.

26. McHutchison JG, Gordon SC, Schiff ER, Shiffman ML, Lee WM, Rustgi VK, et al. Interferon alfa-2b alone or in combination with ribavirin as initial treatment for chronic hepatitis C. Hepatitis Interventional Therapy Group. N Engl J Med. 1998;339(21):1485-92.

27. Tokumoto Y, Hiasa Y, Horiike N, Michitaka K, Matsuura B, Chung RT, et al. Hepatitis C virus expression and interferon antiviral action is dependent on PKR expression. Journal of medical virology. 2007;79(8):1120-1127.

28. El-Dahshan D, Bahy D, Wahid A, Ahmed AE, Hanora A. Two novel SNPs in the promoter region of PKR gene in hepatitis $\mathrm{C}$ patients and their impact on disease outcome and response to treatment. Arab J Gastroenterol. 2018;19(3):106-115.

29. von vorgelegt, Gisa A, Berlin aus. Pathophysiology of Hepatitis E Virus Infection: Viral Evolution During Antiviral Therapy and Virus-specific T Cell Responses. Medizinische Hochschule Hannover. 2015.

30. Arase Y, Ikeda K, Chayama K, Murashima N, Tsubota A, Suzuki Y, et al. Efficacy and changes of the nonstructural 5A GENE by prolonged interferon therapy for patients with hepatitis $\mathrm{C}$ virus genotype $1 \mathrm{~b}$ and a high level of serum HCV-RNA. Intern Med. 1999;38(6):461-6. 31. Aslan N, Bozdayi AM, Cetinkaya H, Sarioglu M, Turkay C, Bozkaya H, et al. The mutations in ISDR of NS5A gene are not associated with response to interferon treatment in Turkish patients with chronic hepatitis $\mathrm{C}$ virus genotype $1 \mathrm{~b}$ infection. Turk $\mathrm{J}$ Gastroenterol. 2004;15(1):21-6.

32. Murayama M, Katano Y, Nakano I, Ishigami M, Hayashi K, Honda T, et al. A mutation in the 
interferon sensitivity-determining region is associated with responsiveness to interferon-ribavirin combination therapy in chronic hepatitis patients infected with a Japan-specific subtype of hepatitis C virus genotype 1B. J Med Virol. 2007;79(1):35-40.

33. Jardim ACG, Yamasaki LHT, de Queiróz ATL, Bittar C, Pinho JRR, Carareto CMA, et al. Quasispecies of hepatitis $C$ virus genotype 1 and treatment outcome with peginterferon and ribavirin. Infect Genet Evol. 2009;9(4):689-98. 34. Zhang L, Han F, Zhang D, Dou X-G. Mutations in different regions of the genome of hepatitis $\mathrm{C}$ virus genotype $1 \mathrm{~b}$ and association with response to interferon therapy. Int $\mathrm{J}$ Mol Med. 2012;30(6):1438-42.

35.Puig-Basagoiti F, Sáiz J-C, Forns X, Ampurdanès S, Giménez-Barcons $M$, Franco $S$, et al. Influence of the genetic heterogeneity of the ISDR and PePHD regions of hepatitis $\mathrm{C}$ virus on the response to interferon therapy in chronic hepatitis C. J Med Virol. 2001;65(1):35-44.

36. Duverlie G, Khorsi H, Castelain S, Jaillon O. Izopet J, Lunel F, Eb F, Penin F, Wychows C. Sequence analysis of the NS5A protein of European hepatitis Cvirus $1 \mathrm{~b}$ isolates and relation to interferon sensitivity. J Gen Virol. 1998;79( Pt 6):1373-81. 